\title{
ORIGINAL ARTICLE \\ Correlates of fruit, vegetable, soft drink, and snack intake among adolescents: the ESSENS study
}

\author{
Mekdes K. Gebremariam*, Sigrun Henjum, Laura Terragni and Liv Elin Torheim \\ Department of Nursing and Health Promotion, Faculty of Health Sciences, Oslo and Akershus University College of \\ Applied Sciences, Oslo, Norway
}

Abstract

Background: Identifying modifiable correlates of dietary behaviors is of utmost importance for the promotion of healthy dietary behaviors.

Objective: This study explores individual, home, and school/neighborhood environmental correlates of dietary behaviors (intake of fruits, vegetables, soft drinks, and unhealthy snacks) among adolescents.

Methods: In total, 742 adolescents with a mean age of $13.6(\mathrm{SD}=0.3)$ were included in this cross-sectional study conducted in 11 secondary schools located in the eastern part of Norway. A web-based questionnaire was used to collect data. Univariable and multivariable linear regression analyses were used to explore factors associated with the dietary behaviors included.

Results: A higher frequency of food/drink purchase in the school canteen was related to a higher consumption of soft drinks and snacks. A higher frequency of food/drink purchase in shops around schools during break or recess was related to a higher consumption of snacks. A higher frequency of food/drink purchase in shops around the neighborhood on the way to and from school was related to a higher consumption of soft drinks. Perceived parental modeling and perceived accessibility at home were found to be positively associated with all dietary behaviors. Perceived parental rules were inversely associated with soft drink and snack consumption; self-efficacy related to healthy eating was positively associated with fruit and vegetable consumption. Other included school and neighborhood environmental correlates were not associated with the dietary behaviors.

Conclusions: There is a need to address the food purchasing behavior of the adolescents using different approaches. The findings also highlight the important role of parents and the home environment for healthy and unhealthy dietary behaviors of adolescents.

Keywords: correlates; dietary behaviors; home; school; neighborhood; environment

Received: 6 June 2016; Revised: 22 August 2016; Accepted: 26 August 2016; Published: 20 September 2016

$\mathrm{O}$ ne of the major public health challenges globally today is the pandemic of overweight and obesity. The problem is particularly pronounced among youth who can suffer from both short- and long-term complications (1-4) including tracking of body weight into adulthood (5). Unhealthy dietary behaviors are among the multiple interacting forces driving this pandemic (6). In this regard, favorable changes in the consumption of fruits, vegetables, soft drinks, and sweets have been documented in the past decade in Norway (7). However, the consumption of fruits and vegetables remains below what is recommended for health, and the consumption of added sugar is high (7-9). It is therefore of utmost importance to investigate the factors influencing dietary behaviors among adolescents.
Ecological models posit that health behaviors are influenced by factors at multiple levels including individual, interpersonal/social, and environmental levels (10). In this regard, individual factors such as preferences and self-efficacy have been identified as important correlates of dietary behaviors; the home environment has also been found to play a crucial role in determining children and adolescents' dietary behaviors (11-16). However, wider environmental (e.g. school and neighborhood) correlates of dietary behaviors have been less explored, although the past decade has seen an increase in studies focusing on such correlates (16). A systematic review of reviews documented that no school, neighborhood, or societal factors were consistently related to dietary behaviors among youth (12). Another systematic review concluded that there was little 
evidence supporting an effect of the retail environment around school on purchasing behavior or on consumption behavior (17). Many studies using multilevel modeling also found low school-level variance in dietary behaviors of children once individual-level characteristics were controlled (18-23). Such findings have at least partly been ascribed to a lack of high-quality studies (17) as well as to the fact that important environmental factors have not been explored. In addition, significant differences exist in the food environment across different settings, in particular in relation to the foods/drinks available at school, contributing to inconsistencies in results. Most studies of school-level correlates of dietary behaviors have been conducted in the USA where the school food environment is different from the European school food environment in general, and the Norwegian school food environment in particular. In Norway, there are no free school lunch programs, and it was documented that $95 \%$ of fifth to seventh graders bring their lunch from home (24). It is prohibited to have vending machines in schools; foods/ drinks are offered via canteens/food booths that might have variable services and opening hours. Therefore, results regarding the influence of the school food environment from countries such as the USA cannot be directly extrapolated to the Norwegian setting. In addition, a recent umbrella review of correlates of dietary behaviors among youth concluded that groups of correlates have often been studied in isolation (16). There is therefore a need for studies that explore simultaneously multiple levels of influence.

Against this background, this study aimed to explore individual, home environmental, and school/neighborhood correlates of the consumption of fruits, vegetables, soft drinks, and unhealthy snacks among adolescents. It was hypothesized, based on existing literature, that the individual and home environmental correlates included would have the most significant contribution in explaining the dietary behaviors of the adolescents. It was also hypothesized that school and neighborhood environmental variables would independently contribute to the prediction of the dietary behaviors included. The participants in this study are young adolescents who are gradually gaining autonomy and are therefore likely to be increasingly influenced by food environment other than the home food environment.

\section{Methods}

\section{Design and sample}

The participants in this study were pupils from 11 secondary schools participating in the Environmental determinantS of dietary BehaviorS among adolescENtS (ESSENS) cross-sectional study. All 12 secondary schools in the Øvre Romerike region located in the eastern part of Norway were invited to participate in the study, and
11 accepted the invitation. In total, 1,163 adolescents in the eighth grade were invited to participate in this study and a total of $781(67 \%)$ received parental consent for participation. In total, 742 adolescents $(64 \%$ of those invited and $95 \%$ of those with parental consent) participated in the study.

Ethical clearance for the study was obtained from the Norwegian Social Science Data Service. Written informed consent was obtained from all parents of participating students.

\section{Data collection and measures}

A web-based questionnaire was used to collect data from the adolescents. The questionnaires were filled in at school and took approximately 30 to $45 \mathrm{~min}$ to complete. Research group members were present during data collection to answer questions and make sure adolescents responded independently from each other. The questionnaire was pretested among a group of adolescents $(n=23)$ of the same age as the study participants, prior to the main study.

\section{Measures}

\section{Dietary behaviors}

Intake of carbonated sugar-sweetened soft drinks (hereafter referred to as soft drinks) during weekdays was assessed using a frequency question with categories ranging from never/seldom to every weekday, and amount in glasses (from one to four or more). Weekend intake was assessed using a question about the amount of soft drink consumed with categories ranging from never/seldom to seven glasses or more. As soft drinks are usually sold in half liter bottles or cans, the participants were informed that $1 / 2$ liter equals three glasses. Weekday and weekend intakes were summed up to create a weekly intake variable. The questions assessing the intake of soft drinks have been validated among 9- and 13-year-old Norwegians using a 4-day precoded food diary as the reference method, and moderate Spearman's correlation coefficients were obtained (25). However, separate assessment of weekday and weekend intake was not made in the validation study.

Consumption of fruits and vegetables (raw and cooked) was assessed using frequency questions with eight response categories ranging from never/seldom to three times per day or more. The questions assessing intake of fruits and vegetables were validated among 11-year-olds with a 7-day food record as the reference method and were found to have a satisfactory ability to rank subjects according to their intake of fruits and vegetables (26).

The consumption of snacks [sweet snacks (candies/ chocolate), fatty snacks (e.g. potato chips), and sweet biscuits/muffins and similar] was assessed using three questions with seven response categories ranging from 
never/seldom to two times per day or more; frequencies of consumption of all the snacks were added to create a total snack intake variable.

Acceptable to moderate test-retest reliability was obtained for these measures of dietary behaviors in a previous Norwegian study conducted among 11-year-olds (27).

Perceived accessibility of vegetables was assessed using a scale with four items (e.g. "we vary the types of vegetables served for dinner during a week'); perceived accessibility of fruits was assessed using a scale with three items (e.g. 'we vary the types of fruits that we have during the course of the week'); perceived accessibility of soft drinks was assessed using a scale with three items (e.g. 'we usually have soft drinks for dinner on weekend days'); and perceived accessibility of snacks was assessed using a scale with three items (e.g. 'we usually have sweet or fatty foods served for dessert or as snacks on weekdays'). A five-point Likert scale with answer categories ranging from 'totally disagree to totally agree' was used.

Perceived parental rules related to the consumption of vegetables were assessed using a scale with two items (e.g. 'I can eat vegetables whenever I want'); a similar scale was used to assess the perceived parental rule related to fruit consumption. Perceived parental rules for the consumption of soft drinks were assessed using a scale with four items (e.g. "we have rules for when I can drink soft drinks'); perceived parental rules related to snack consumption was assessed using a single item ('when we have sweet or fatty snacks available, I can eat as much as I want'). A five-point Likert scale with answer categories ranging from 'totally disagree to totally agree' was used.

The items assessing perceived rules and accessibility of vegetables and soft drinks have previously shown evidence of validity among 14-year-olds (28).

Perceived parental modeling of fruit intake and of vegetable intake was assessed using a scale with two items. The measures were adopted from the Pro Children study and were found to have adequate test-retest reliability among 10-11-year-old European children (29). Parental modeling of soft drink consumption was assessed using the question 'How often do your parents drink soft drinks with sugar?' This question has shown evidence of testretest reliability among 10-12-year-old European children (30). A similar scale was used to assess parental consumption of unhealthy snacks.

Self-efficacy related to the consumption of healthy foods was assessed using a scale with six items [e.g. Whenever I have a choice of the food I eat ..., I find it difficult to choose low-fat foods (e.g. fruit or skimmed milk rather than 'full cream milk')]. The scale has been found to have adequate reliability and factorial validity among 13-year-olds (31).

All scales had acceptable to moderate internal consistency reliability in the present sample (ICC: $0.50-0.80$ ).
The adolescents were asked about the presence of food sales outlets (e.g. supermarket, kiosk, and gas station) in a walking distance from their school (with answer categories 'none', 'yes, one', 'yes, two', and 'yes, more than two'). The question was adopted from a previous Norwegian study (23). They were asked how often they bought foods/drinks in these shops during breaks or recess. They were also asked how often they purchased foods or drinks from school canteens and on their way to and from school (answer categories ranging from 'never' to 'every day'). The frequency of purchase of foods/ drinks was then recategorized into never, once a week, and more than once a week based on the distribution of the variables.

The perceived availability of fruits, vegetables, and unhealthy snacks in shops around school and in shops in the neighborhood was also assessed (e.g. a lot of fresh and varied fruits and vegetables that I like are available). Perceived accessibility of fruits and vegetables in these shops was asked using the question 'There are a lot of fruits and vegetables in a form that is easy to consume'. Perceived accessibility of soft drinks or snacks compared to fruits or vegetables in shops around schools or in the neighborhood was assessed using the question 'It is easier to find soft drinks and snacks in the shops than it is to find fruits or vegetables'. Perceived price of soft drinks and snacks compared to fruits and vegetables was explored using the question 'It is cheaper to buy soft drinks or snacks (e.g. biscuits, chips) than it is to buy fruits or vegetables'. Answer categories ranged from 'completely agree' to 'completely disagree'.

Information at school regarding food/nutrition was assessed using a scale with two items (e.g. 'food and nutrition is a topic that my teachers talk about often'). The internal consistency for the scale was moderate $(\mathrm{ICC}=0.78)$. Perceived rules regarding foods and drinks allowed at school were assessed using the question: 'We have rules at school regarding the foods/drinks we should or should not bring to school' (answer categories ranging from 'completely agree' to 'completely disagree'). The question was adopted from a previous Norwegian study (23).

\section{Sociodemographic correlates}

Information on parental education was gathered as part of the parental informed consent for the adolescent. It was categorized into low (12 years of education or less, which corresponded to secondary education or lower) and high (13 years of education and more, which corresponded to university or college attendance). Educational status of the parent with the longest education or else the one available was used in the analyses.

Participants were divided into either ethnic Norwegian or ethnic minority. Ethnic minorities were defined as 
those having both parents born in a country other than Norway (32).

\section{Statistical analyses}

Because schools were the unit of measurement in this study, we checked for clustering effect through the linear mixed model procedure. Only $\leq 3 \%$ of the unexplained variance in the dietary behaviors investigated was at the school level. Hence, adjustment for clustering effect was not done.

Descriptive analyses were first conducted. Univariable linear regression analyses were then used to explore factors at the individual (including sociodemographic characteristics), interpersonal, home environmental, and school/neighborhood environmental levels associated with the different dietary behaviors. Thereafter, variables significant at the 0.2 level on univariable regression were entered in multivariable regression models. Assumptions for the analyses were checked and considered acceptable. All analyses were conducted using SPSS version 22 .

\section{Results}

The sociodemographic characteristics of the adolescents are described in Table 1. The mean age was 13.6 $(\mathrm{SD}=0.3)$, and $53 \%$ of participants were females. Only $9 \%$ of adolescents were of an ethnic minority background and $40 \%$ had parents with a low level of education. The mean consumption of soft drinks was $700 \mathrm{~mL} /$ week. The frequency of fruit, vegetable, and snack consumption was $6.9,8.8$, and 4.5 times/week, respectively.

Table 2 shows the results of the descriptive analyses of the correlates included in the study. The lowest mean values were obtained for the perceived accessibility of unhealthy snacks and soft drinks at home. The highest values were obtained for permissive parental rules related to vegetable and fruit intake. The mean number of food sales outlets around schools was 2.2, and only $4 \%$ of participants reported that there were no food sales outlets in a walking distance from their school. In total, $73 \%$ of participants reported that they never purchased foods/ drinks in shops around schools during breaks or recess;

Table 1. Sociodemographic characteristics and dietary behaviors of the study sample $(n=742)$

$\begin{array}{lc}\text { Age (years) } & 13.6(0.3) \\ \text { Gender }(\% \text { girls) } & 53 \\ \text { Parental education }\left(\% l^{\prime}{ }^{\mathrm{a}}\right) & 40 \\ \text { Ethnicity (\% ethnic minority) } & 9 \\ \text { Soft drink consumption (dl/week) } & 7.0(6.5-7.4) \\ \text { Fruit intake (times/week) } & 6.9(6.5-7.4) \\ \text { Vegetable intake (times/week) } & 8.8(8.2-9.2) \\ \text { Snack intake (times/week) } & 4.5(4.2-4.7)\end{array}$

Results are presented as mean and confidence interval or percentages. ${ }^{a}$ Low education is defined as having 12 years of education or less.
Table 2. Descriptive analysis of potential correlates of dietary behaviors among study participants $(n=742)$

\begin{tabular}{|c|c|c|}
\hline & $\begin{array}{l}\text { Mean } \\
\text { (SD) or \% }\end{array}$ & Range \\
\hline Perceived parental modeling of soft drink intake & $2.71(0.83)$ & $\mathrm{I}-5$ \\
\hline Perceived accessibility of soft drinks at home & $2.57(1.14)$ & $0-5$ \\
\hline Perceived parental rules related to soft drinks & $4.28(1.11)$ & $1-6$ \\
\hline Perceived parental modeling of snack intake & $2.70(0.62)$ & $1-5$ \\
\hline Perceived accessibility of snacks at home & $2.49(0.79)$ & $\mathrm{I}-5$ \\
\hline Perceived parental rules related to snacks & $3.90(1.23)$ & $\mathrm{I}-5$ \\
\hline Perceived parental modeling of vegetable intake & $3.68(0.97)$ & $1-5$ \\
\hline Perceived accessibility of vegetables at home & $4.09(0.77)$ & $\mathrm{I}-5$ \\
\hline Perceived parental rules related to vegetables & $4.55(0.7 I)$ & $\mathrm{I}-5$ \\
\hline Perceived parental modeling of fruit intake & $4.14(0.87)$ & $\mathrm{I}-5$ \\
\hline Perceived accessibility of fruits at home & $3.89(0.78)$ & $1-5$ \\
\hline Perceived parental rules related to fruits & $4.56(0.68)$ & $\mathrm{I}-5$ \\
\hline Self-efficacy related to healthy eating & $3.48(0.65)$ & $1-5$ \\
\hline Number of food sales outlets around school ${ }^{a}$ & $2.19(0.93)$ & $0-3$ \\
\hline \multicolumn{3}{|l|}{ Food/drink purchase in school canteen } \\
\hline Never & $67 \%$ & \\
\hline Once a week & $20 \%$ & \\
\hline Twice or more per week & $13 \%$ & \\
\hline \multicolumn{3}{|l|}{ Food/drink purchase in neighborhood shops ${ }^{b}$} \\
\hline Never & $66 \%$ & \\
\hline Once a week & $24 \%$ & \\
\hline Twice or more per week & $10 \%$ & \\
\hline \multicolumn{3}{|l|}{ Food/drink purchase in shops around school ${ }^{c}$} \\
\hline Never & $73 \%$ & \\
\hline Once a week & $16 \%$ & \\
\hline Twice or more per week & $11 \%$ & \\
\hline Perceived FV availability in neighborhood shops & $4.24(1.02)$ & $\mathrm{I}-5$ \\
\hline Perceived FV accessibility in neighborhood shops & $4.09(1.08)$ & $\mathrm{I}-5$ \\
\hline $\begin{array}{l}\text { Perceived accessibility of SD and snacks in } \\
\text { neighborhood }\end{array}$ & $3.03(1.24)$ & $1-5$ \\
\hline $\begin{array}{l}\text { Perceived availability of SD and snacks in } \\
\text { neighborhood }\end{array}$ & $3.88(1.19)$ & $\mathrm{I}-5$ \\
\hline Perceived price of SD and snacks compared to FV & $3.08(1.23)$ & $1-5$ \\
\hline Perceived school food rules & $3.56(1.36)$ & $\mathrm{I}-5$ \\
\hline Information at school regarding food and nutrition & $2.68(1.05)$ & $1-5$ \\
\hline
\end{tabular}

$\mathrm{SD}$, soft drinks; FV, fruits and vegetables.

${ }^{a}$ In a walking distance from school, bon the way to and from school, cduring breaks or recess.

$11 \%$ reported doing so twice or more per week. Similarly, $66 \%$ of participants reported that they never purchased foods/drinks from neighborhood shops on their way to and from school, whereas $24 \%$ and $10 \%$ reported doing so once a week and twice or more per week, respectively. No food/drink purchase in school canteen was reported by $67 \%$ of participants; $20 \%$ reported purchasing foods/ drinks once a week and $13 \%$ twice or more per week.

In the final adjusted models, the following factors were found to be associated with soft drink consumption (d1/week): gender (reference $=$ female) $\mathrm{B}=1.33$ (confidence interval (CI): 0.48-2.17), perceived parental modeling 
$\mathrm{B}=0.63$ (CI: 0.06-1.21), perceived accessibility at home $\mathrm{B}=1.47$ (CI: 1.02-1.92), perceived parental rules $\mathrm{B}=-1.58$ (CI: -2.01 to -1.15 ), purchase of food/drink at the school canteen (high vs. low) $\mathrm{B}=2.10$ (CI: 0.74-3.45), and purchase of food/drinks on the way to and from school (high vs. low) $\mathrm{B}=2.87$ (CI: 1.31-4.43). The factors found to be associated with snack consumption in the final adjusted models were perceived parental modeling $\mathrm{B}=0.43(95 \% \mathrm{CI}$ : $0.01-$ $0.85)$, perceived accessibility at home $\mathrm{B}=1.0(95 \% \mathrm{CI}: 0.66-$ $1.35)$, perceived parental rules $\mathrm{B}=-0.22(95 \% \mathrm{CI}:-0.43$ to -0.01 ), self-efficacy related to healthy eating $B=-0.90$ ( $95 \%$ CI: -1.29 to -0.51$)$, purchase of food/drink in the school canteen (high vs. low) B $=0.92$ (95\% CI: 0.13-1.71), and food/drink purchase around school during recessand breaks (high vs. low) $\mathrm{B}=1.57$ (95\% CI: 0.73-2.41). Table 3 shows the results of the multivariable regression analyses exploring correlates of soft drink and snack consumption.
The factors found to be associated with fruit intake in the final adjusted models were perceived parental modeling $\mathrm{B}=0.54$ (95\% CI: 0.02-1.06), perceived accessibility at home $\mathrm{B}=1.38$ (95\% CI: 0.76-1.99), and selfefficacy regarding healthy eating $B=2.69$ (95\% CI: $2.01-$ 3.38). The factors found to be associated with vegetable intake were perceived parental modeling $\mathrm{B}=0.58(95 \%$ CI: 0.09-1.07), perceived accessibility at home $\mathrm{B}=2.98$ (95\% CI: 2.28-3.68), and self-efficacy regarding healthy eating $\mathrm{B}=2.20$ (95\% CI: $1.46-2.94)$. Table 4 shows the results of the multivariable regression analyses exploring correlates of fruit and vegetable consumption.

\section{Discussion}

The aim of this study was to explore individual, home environmental, and school/neighborhood environmental correlates of fruit, vegetable, soft drink, and unhealthy snack consumption among adolescents. The adolescents'

Table 3. Correlates of soft drink and snack consumption among adolescents, $n=742$

\begin{tabular}{|c|c|c|}
\hline & $\mathrm{B}$ and $\mathrm{Cl}$ & $P$ \\
\hline \multicolumn{3}{|l|}{ Soft drink consumption ( $\mathrm{dl} /$ week) } \\
\hline Gender (males) & $1.33(0.48-2.17)$ & 0.002 \\
\hline Parental education & $-0.21(-1.08-0.66)$ & 0.64 \\
\hline Perceived parental modeling & $0.63(0.06-1.2 I)$ & 0.03 \\
\hline Perceived accessibility at home & $1.47(1.02-1.92)$ & $<0.001$ \\
\hline Perceived parental rules & $-1.58(-2.01$ to -1.15$)$ & $<0.001$ \\
\hline Self-efficacy regarding healthy eating & $-0.58(-1.24-0.08)$ & 0.08 \\
\hline Perceived FV availability in neighborhood shops & $-0.40(-0.80-0.02)$ & 0.06 \\
\hline Food/drink purchase in school canteen (high) & $2.10(0.74-3.45)$ & 0.002 \\
\hline Food/drink purchase in school canteen (medium) & $0.03(-1.06-1.12)$ & 0.96 \\
\hline Food/drink purchase in neighborhood shops ${ }^{a}$ (high) & $2.87(1.31-4.43)$ & $<0.001$ \\
\hline Food/drink purchase in neighborhood shops ${ }^{a}$ (medium) & $-0.41(-1.44-0.62)$ & 0.44 \\
\hline Food/drink purchase in shops around school ${ }^{\mathrm{b}}$ (high) & $-0.92(-2.36-0.52)$ & 0.21 \\
\hline Food/drink purchase in shops around school ${ }^{\mathrm{b}}$ (medium) & $-0.85(-2.0-0.30)$ & 0.15 \\
\hline \multicolumn{3}{|l|}{ Intake of snacks (times/week) } \\
\hline Perceived parental modeling & $0.43(0.01-0.85)$ & 0.046 \\
\hline Perceived accessibility at home & $1.0(0.66-1.35)$ & $<0.001$ \\
\hline Perceived parental rules & $-0.22(-0.43$ to -0.01$)$ & 0.04 \\
\hline Self-efficacy regarding healthy eating & $-0.90(-1.29$ to $-0.5 \mathrm{I})$ & $<0.001$ \\
\hline Perceived availability in neighborhood shops & $0.14(-0.08-0.35)$ & 0.21 \\
\hline Perceived price compared to fruits and vegetables & $0.20(0.00-0.40)$ & 0.05 \\
\hline Food/drink purchase in school canteen (high) & $0.92(0.13-1.7 I)$ & 0.02 \\
\hline Food/drink purchase in school canteen (medium) & $-0.27(-0.9-0.37)$ & 0.42 \\
\hline Food/drink purchase in neighborhood shops ${ }^{\mathrm{a}}$ (high) & $0.29(-0.64-1.21)$ & 0.54 \\
\hline Food/drink purchase in neighborhood shops ${ }^{a}$ (medium) & $-0.28(-0.89-0.32)$ & 0.36 \\
\hline Food/drink purchase in shops around school ${ }^{\mathrm{b}}$ (high) & $\mathrm{I} .57(0.73-2.4 \mathrm{I})$ & $<0.001$ \\
\hline Food/drink purchase in shops around school ${ }^{b}$ (medium) & $0.15(-0.53-0.83)$ & 0.67 \\
\hline
\end{tabular}

FV, fruits and vegetables.

${ }^{a}$ On the way to and from school, bduring recess or breaks.

Results were obtained using multiple linear regression analyses, and only factors significant at the 0.2 level on univariable regression were included in this model. Frequency of food purchase is defined as high when it occurs twice or more per week and as medium when it occurs once a week. The reference category includes those who report no purchase of food/drinks. 
Table 4. Correlates of fruit and vegetable consumption among adolescents, $n=741$

\begin{tabular}{|c|c|c|}
\hline & $\mathrm{B}$ and $\mathrm{Cl}$ & $P$ \\
\hline \multicolumn{3}{|l|}{ Fruit consumption (times/week) } \\
\hline Ethnicity & $1.28(-0.23-2.79)$ & 0.09 \\
\hline Perceived parental modeling & $0.54(0.02-1.06)$ & 0.04 \\
\hline Perceived accessibility at home & $1.38(0.76-1.99)$ & $<0.001$ \\
\hline Perceived parental rules & $-0.26(-0.93-0.41)$ & 0.45 \\
\hline $\begin{array}{l}\text { Self-efficacy regarding healthy } \\
\text { eating }\end{array}$ & $2.69(2.01-3.38)$ & $<0.001$ \\
\hline $\begin{array}{l}\text { Perceived } \mathrm{FV} \text { availability in } \\
\text { neighborhood shops }\end{array}$ & $0.07(-0.36-0.50)$ & 0.74 \\
\hline Perceived food rules at school & $-0.23(-0.54-0.08)$ & 0.15 \\
\hline \multicolumn{3}{|l|}{ Vegetable consumption (times/week) } \\
\hline Perceived parental modeling & $0.58(0.09-1.07)$ & 0.02 \\
\hline Perceived accessibility at home & $2.98(2.29-3.68)$ & $<0.001$ \\
\hline Perceived parental rules & $0.08(-0.6 \mathrm{I}-0.77)$ & 0.82 \\
\hline $\begin{array}{l}\text { Self-efficacy regarding healthy } \\
\text { eating }\end{array}$ & $2.20(1.46-2.94)$ & $<0.001$ \\
\hline $\begin{array}{l}\text { Perceived } \mathrm{FV} \text { availability in } \\
\text { neighborhood shops }\end{array}$ & $-0.32(-0.77-0.12)$ & 0.15 \\
\hline
\end{tabular}

FV, fruits and vegetables.

Results were obtained using multiple linear regression analyses, and only factors significant at the 0.2 level on univariable regression were included in this model.

food purchasing behavior at school and in the neighborhood was associated with soft drink and snack consumption. The other school and neighborhood environmental correlates were not associated with the dietary behaviors of the adolescents. Parental modeling and perceived accessibility at home were found to be positively associated with all the dietary behaviors. Parental rules were associated with soft drink and snack consumption; self-efficacy related to healthy eating was associated with fruit and vegetable consumption.

As hypothesized, home environmental variables were found to be the most important correlates of the dietary behaviors included. As previously documented in the literature, parental modeling (11-14) and perceived accessibility at home $(13,15)$ were found to be positively associated with all the dietary behaviors included. Self-efficacy related to healthy eating was also strongly positively related to the consumption of fruits and vegetables and inversely related to the consumption of unhealthy snacks. Self-efficacy has been found to be a strong correlate of healthy behaviors among adolescents including dietary behaviors (15). Parents can play a role in the enhancement of their adolescents' self-efficacy toward healthy eating that would result in favorable dietary behaviors, which might further enhance self-efficacy. There were also parental educational differences in soft drink consumption on univariable analysis. This association became insigni- ficant in the final adjusted model, indicating that variables included in the model were potentially mediators of the socioeconomic differences in soft drink consumption. Indeed, separate analyses (results not shown) showed that there were socioeconomic differences in the correlates that were significantly associated with soft drink consumption. Factors such as parental modeling and accessibility at home have previously been found to mediate socioeconomic differences in soft drink consumption (33-35).

The frequency of food purchase in the school canteen was positively related to the intake of unhealthy snacks and soft drinks. The Norwegian recommendations for school food state that the offer of cakes and other sweet or fatty products be limited to special occasions. These recommendations also state that soft drinks should not be offered at school (36). However, in a qualitative component of the ESSENS study, which included observations of canteens in selected schools, it was found that some unhealthy foods and drinks were offered in some schools, in addition to healthier food alternatives (unpublished data). A previous study from the USA found that middle school students purchased unhealthy foods such as chips, soda, and soft drinks at school even when healthier alternatives were available (37). In another study, availability at school was related to the consumption of soft drinks and unhealthy snacks, but not with fruit and vegetable consumption (38). Limiting the availability of unhealthy foods and drinks from school canteens by ensuring that national guidelines for foods at school are properly implemented is therefore crucial.

The frequency of food purchase in neighborhood shops on the way to and from school was positively related to the consumption of soft drinks. The frequency of food purchase in shops around schools during breaks or recess was positively related to the consumption of unhealthy snacks. It is worth noting that there might be some overlap between these shops, as the shops around school might be the ones most accessible on the way to and from school for some, in particular those living in close proximity of their school. Food purchase away from home has been associated with unfavorable eating behaviors and weight outcomes in previous studies, although the type of food purchased and of food outlets explored varied between studies (39-41). In this regard, parents should encourage their children to purchase healthy foods and whenever possible limit their adolescents' food purchase by providing fewer financial resources for doing so. There was also a borderline statistically significant inverse association between the perceived price of snacks compared to fruits and vegetables and the consumption of snacks, that is, those who perceived the price of snacks to be lower consumed more snacks. Food prices have been shown to be key correlates of healthy and unhealthy 
food consumption (42-44) and can therefore serve as one of the entry points for interventions aimed at improving adolescents' dietary behaviors.

In this study, school and neighborhood environmental variables did not appear to have a significant influence on the dietary behaviors of the adolescents, in particular fruit and vegetable consumption. There might be several reasons for these findings. Existing data indicate that $95 \%$ of fifth to seventh graders in Norway bring their school lunch from home (24) which is likely similar among eighth graders. Therefore, most of the consumption of fruits and vegetables is likely to be either at home or from fruits and vegetables brought from home. It is also possible that there is homogeneity in the factors of interest between schools and neighborhoods although there was diversity in the perceptions reported. Consequently, actual school and neighborhood correlates might not have had enough variability that would allow for associations with dietary behaviors to be picked, for example, shops around schools might have similar availability/accessibility of foods across the included schools. Indeed, some ceiling effect was apparent for the measure of perceived fruit and vegetable availability in neighborhood shops. Future studies combining objective and subjective measures of the school and neighborhood environment in the same sample are needed in this regard. Such studies would allow for the assessment of similarities and differences in associations when subjective and objective measures are used. The latter might provide a more accurate assessment; however, how these environmental factors are perceived by the adolescents might be more relevant in influencing their behaviors.

The strengths of the study include the large number of correlates at multiple levels that were included. The sample size was also large; the response rate at the school level was very high and was moderate at the parental level. The weaknesses include the cross-sectional data that does not allow for any causal inference to be made. The use of self-report can lead to problems of validity and reliability, in particular among young children. Several of the correlates included, however, had displayed evidence of reliability and/or validity in previous studies among adolescents in a similar age group. There is, however, a scarcity of validity and reliability tested measures assessing the perceived school and neighborhood food environment including the measures used in this study. Finally, only carbonated sugar-sweetened soft drinks were included in this study; future studies should include other sugarsweetened beverages such as cordials and energy drinks.

\section{Conclusions}

Food purchasing behavior at school and on the way to and from school was found to be related to the intake of soft drinks and snacks. Perceived accessibility and parental modeling were related to all dietary behaviors; parental rules were related to soft drink and snack intake. Other school and neighborhood environmental variables were unrelated to the dietary behaviors included. There is therefore a need to address the food purchasing behavior of the adolescents using different approaches such as limiting the availability of unhealthy foods and drinks from school canteens. The findings also highlight the important role of parents and the home environment for healthy and unhealthy dietary behaviors of adolescents.

\section{Authors' contributions}

MKG designed the study, planned the project, participated in the data collection, conducted the statistical analyses, and wrote the first draft of the manuscript. LET, LT, and SH participated in project planning and implementation. All authors have critically revised the manuscript, and read and approved the final version of the manuscript.

\section{Acknowledgements}

The ESSENS study is a collaborative project between the Oslo and Akershus University College of Applied Sciences and the public health project Folkehelseforum Øvre Romerike (FØR). The authors thank all the participants who took part in this study. They are particularly grateful to Elisabeth Hurum and Jorunn Utne for their work with recruitment and data collection.

\section{Conflict of interest and funding}

The authors declare that they have no competing interests. The ESSENS project was funded by internal funds from Oslo and Akershus University College of Applied Sciences.

\section{References}

1. Dietz WH. Health consequences of obesity in youth: childhood predictors of adult disease. Pediatrics 1998; 101: 518-25.

2. Daniels SR, Arnett DK, Eckel RH, Gidding SS, Hayman LL, Kumanyika S, et al. Overweight in children and adolescents: pathophysiology, consequences, prevention, and treatment. Circulation 2005; 111: 1999-2012.

3. Biro FM, Wien M. Childhood obesity and adult morbidities. Am J Clin Nutr 2010; 91: 1499S-505S.

4. Reilly JJ, Kelly J. Long-term impact of overweight and obesity in childhood and adolescence on morbidity and premature mortality in adulthood: systematic review. Int J Obes 2011; 35: 891-8.

5. Singh AS, Mulder C, Twisk JW, van Mechelen W, Chinapaw MJ. Tracking of childhood overweight into adulthood: a systematic review of the literature. Obes Rev 2008; 9: 474-88.

6. Swinburn BA, Sacks G, Hall KD, McPherson K, Finegood DT, Moodie ML, et al. The global obesity pandemic: shaped by global drivers and local environments. Lancet 2011; 378: 804-14.

7. Fismen AS, Smith OR, Torsheim T, Rasmussen M, Pedersen Pagh T, Augustine L, et al. Trends in food habits and their relation to socioeconomic status among Nordic adolescents 2001/2002-2009/20. PLoS One 2016; 11: e0148541. 
8. Bjelland M, Lien N, Grydeland M, Bergh IH, Anderssen SA, Ommundsen $\mathrm{Y}$, et al. Intakes and perceived home availability of sugar-sweetened beverages, fruit and vegetables as reported by mothers, fathers and adolescents in the HEIA (Health In Adolescents) study. Public Health Nutr 2011; 14: 2156-65.

9. Bere E, Glomnes ES, te Velde SJ, Klepp KI. Determinants of adolescents' soft drink consumption. Public Health Nutr 2008; 11: 49-56.

10. Sallis JF, Owen N, Fisher EB. Ecological models of health behaviour. In: Glanz Z, Rimer BK, Viswanath K, eds. Health behaviour and health education: theory, research and practice. 4th ed. San Francisco, CA: Jossey-Bass; 2008; 465-482.

11. Pearson N, Biddle SJH, Gorely T. Family correlates of fruit and vegetable consumption in children and adolescents: a systematic review. Public Health Nutr 2009; 12: 267-83.

12. De Vet E, De Ridder DT, De Wit JB. Environmental correlates of physical activity and dietary behaviours among young people: a systematic review of reviews. Obes Rev 2011; 12: e130-42.

13. Van der Horst K, Oenema A, Ferreira I, Wendel-Vos W, Giskes $\mathrm{K}$, Van Lenthe $\mathrm{F}$, et al. A systematic review of environmental correlates of obesity-related dietary behaviors in youth. Health Educ Res 2007; 22: 203-26.

14. McClain AD, Chappuis C, Nguyen-Rodriguez ST, Yaroch AL, Spruijt-Metz D. Psychosocial correlates of eating behavior in children and adolescents: a review. Int $\mathbf{J}$ Behav Nutr Phys Act 2009; 6: 54.

15. Rasmussen M, Krølner R, Klepp K-I, Lytle L, Brug J, Bere E, et al. Determinants of fruit and vegetable consumption among children and adolescents: a review of the literature. Part I: quantitative studies. Int J Behav Nutr Phys Act 2006; 3: 22.

16. Sleddens EF, Kroeze W, Kohl LF, Bolten LM, Velema E, Kaspers PJ, et al. Determinants of dietary behavior among youth: an umbrella review. Int J Behav Nutr Phys Act 2015; 12: 7

17. Williams J, Scarborough P, Matthews A, Cowburn G, Foster $\mathrm{C}$, Roberts N, et al. A systematic review of the influence of the retail food environment around schools on obesity-related outcomes. Obes Rev 2014; 15: 359-74.

18. Krølner R, Due P, Rasmussen M, Damsgaard MT, Holstein BE, Klepp KI, et al. Does school environment affect 11-yearolds' fruit and vegetable intake in Denmark? Soc Sci Med 2009; 68: $1416-24$.

19. Vereecken CA, Bobelijn K, Maes L. School food policy at primary and secondary schools in Belgium-Flanders: does it influence young people's food habits? Eur J Clin Nutr 2005; 59: 271-7.

20. Van der Horst K, Timperio A, Crawford D, Roberts R, Brug J, Oenema A. The school food environment associations with adolescent soft drink and snack consumption. Am J Prev Med 2008; 35: 217-23.

21. Maes L, Lievens J. Can the school make a difference? A multilevel analysis of adolescent risk and health behaviour. Soc Sci Med 2003; 56: 517-29.

22. Johansen A, Rasmussen S, Madsen M. Health behavior among adolescents in Denmark: influence of school class and individual risk factors. Scand J Public Health 2006; 34: 32-40.

23. Gebremariam MK, Andersen LF, Bjelland M, Klepp KI, Totland TH, Bergh IH, et al. Does the school food environment influence the dietary behaviours of Norwegian 11-year-olds? The HEIA study. Scand J Public Health 2012; 40: 491-7.

24. Kunnskapsdepartementet. Skolemåltidet i grunnskolen. Kunnskapsgrunnlag, nytte og kostnadsvirkninger og vurdering av ulike skolemåltidsmodeller. Rapport fra arbeidsgruppe nedsatt av Kunnskapsdepartementet [The school meal in the primary school. Knowledge base, cost-benefit analysis and assessment of different models for school meals. Report from a working group appointed by the Ministry of Education and Research]. (In Norwegian). 2006; Available online at: https://www.regjeringen.no/globalassets/upload/kilde/kd/rap/2006/0008/ddd/pdfv/28 4882-skolemaltid_26.06.06.pdf

25. Lillegaard IT, Overby NC, Andersen LF. Evaluation of a short food frequency questionnaire used among Norwegian children. Food Nutr Res 2012; 56: 6399, doi: http://dx.doi.org/10.3402/ fnr.v56i0.6399

26. Haraldsdóttir J, Thórsdóttir I, de Almeida MD, Maes L, Pérez Rodrigo C, Elmadfa I, et al. Validity and reproducibility of a precoded questionnaire to assess fruit and vegetable intake in European 11- to 12-year-old schoolchildren. Ann Nutr Metab 2005; 49: 221-7.

27. Lien N, Bjelland M, Bergh IH, Grydeland M, Anderssen SA, Ommundsen Y, et al. Design of a 20-month comprehensive, multicomponent school-based randomised trial to promote healthy weight development among 11-13 year olds: the health in adolescents study. Scand J Public Health 2010; 38(5 Suppl): $38-51$.

28. Bjelland M, Hausken SE, Sleddens EF, Andersen LF, Lie HC, Finset A, et al. Development of family and dietary habits questionnaires: the assessment of family processes, dietary habits and adolescents' impulsiveness in Norwegian adolescents and their parents. Int J Behav Nutr Phys Act 2014; 11: 130

29. De Bourdeaudhuij I, Klepp KI, Due P, Rodrigo CP, de Almeida $\mathrm{M}$, Wind $\mathrm{M}$, et al. Reliability and validity of a questionnaire to measure personal, social and environmental correlates of fruit and vegetable intake in 10-11-year-old children in five European countries. Public Health Nutr 2005; 8: 189-200.

30. Singh AS, Vik FN, Chinapaw MJ, Uijtdewilligen L, Verloigne M, Fernández-Alvira JM, et al. Test-retest reliability and construct validity of the ENERGY-child questionnaire on energy balance-related behaviours and their potential determinants: the ENERGY-project. Int J Behav Nutr Phys Act 2011; 8: 136.

31. Dewar DL, Lubans DR, Plotnikoff RC, Morgan PJ. Development and evaluation of social cognitive measures related to adolescent dietary behaviors. Int J Behav Nutr Phys Act 2012; 9: 36.

32. Lie B. Immigration and immigrants: statistisk sentralbyrå. Oslo, Norway: Statistics Norway; 2002.

33. De Coen V, Vansteelandt S, Maes L, Huybrechts I, De Bourdeaudhuij I, Vereecken C. Parental socioeconomic status and soft drink consumption of the child. The mediating proportion of parenting practices. Appetite 2012; 59: 76-80.

34. Totland TH, Lien N, Bergh IH, Bjelland M, Gebremariam MK, Klepp KI, et al. The relationship between parental education and adolescents' soft drink intake from the age of 11-13 years, and possible mediating effects of availability and accessibility. Br J Nutr 2013; 110: 926-33.

35. Hilsen M, te Velde SJ, Bere E, Brug J. Predictors and mediators of differences in soft drinks consumption according to gender and plans of further education among Norwegian secondaryschool children. Public Health Nutr 2013; 16: 1250-6.

36. Helsedirektoratet. Mat og måltider i skolen. Nasjonal faglig retningslinje for mat og måltider i skolen. 2015 [The Directorate of Health. Food and meals in the school. National guidelines for school food and meals. 2015]. Available online at: https:// helsedirektoratet.no/retningslinjer/mat-og-maltider-i-skolen

37. Park S, Sappenfield WM, Huang Y, Sherry B, Bensyl DM. The impact of the availability of school vending machines on eating behavior during lunch: the Youth Physical Activity and Nutrition Survey. J Am Diet Assoc 2010; 110: 1532-6.

38. Cisse-Egbuonye N, Liles S, Schmitz KE, Kassem N, Irvin VL, Hovell MF. Availability of vending machines and school stores in California schools. J Sch Health 2016; 86: 48-53. 
39. Poti JM, Slining MM, Popkin BM. Where are kids getting their empty calories? Stores, schools, and fast-food restaurants each played an important role in empty calorie intake among US children during 2009-2010. J Acad Nutr Diet 2014; 114: 908-17.

40. French SA, Story M, Neumark-Sztainer D, Fulkerson JA, Hannan P. Fast food restaurant use among adolescents: associations with nutrient intake, food choices and behavioral and psychosocial variables. Int $\mathbf{J}$ Obes Relat Metab Disord 2001; 25: 1823-33.

41. Thompson OM, Ballew C, Resnicow K, Must A, Bandini LG, $\mathrm{Cyr} \mathrm{H}$, et al. Food purchased away from home as a predictor of change in BMI z-score among girls. Int J Obes Relat Metab Disord 2004; 28: 282-9.

42. Epstein LH, Dearing KK, Paluch RA, Roemmich JN, Cho D. Price and maternal obesity influence purchasing of low- and high-energy-dense foods. Am J Clin Nutr 2007; 86: 914-22.
43. Levy DT, Friend KB, Wang YC. A review of the literature on policies directed at the youth consumption of sugar sweetened beverages. Adv Nutr 2011; 2: 182S-200S.

44. French SA. Pricing effects on food choices. J Nutr 2003; 133: $841 \mathrm{~S}-3 \mathrm{~S}$

\section{*Mekdes K. Gebremariam}

Department of Nursing and Health Promotion

Faculty of Health Sciences

Oslo and Akershus University College of Applied Sciences

P.O. Box 4 Olavs Plass Street, NO-0I30 Oslo

Norway

Email: mekdes.gebremariam@medisin.uio.no 